\title{
Acidic Sphingomyelinase Controls Hepatic Stellate Cell Activation and in Vivo Liver Fibrogenesis
}

\author{
Anna Moles, ${ }^{, \dagger}$ Núria Tarrats, ${ }^{* \dagger}$ Albert Morales, ${ }^{* \dagger}$ \\ Marlene Domínguez, ${ }^{*}$ Ramón Bataller, ${ }^{*}$ \\ Juan Caballería, ${ }^{\star}$ Carmen García-Ruiz, ${ }^{*}$ \\ José C. Fernández-Checa, ${ }^{\star \star \ddagger}$ and \\ Montserrat Marí ${ }^{\dagger}$ \\ From the Institut d'Investigacions Biomèdiques August Pi i Sunyer," \\ Liver Unit, Hospital Clinic, Centre d'Investigació Biomèdica Esther \\ Koplowitz, Centro de Investigación Biomédicas en Red en el Área \\ temática de Enfermedades Hepáticas y Digestivas; Department of \\ Cell Death and Proliferation, ${ }^{\dagger}$ Consejo Superior de Investigaciones \\ Cientificas Instituto de Investigaciones Biomédicas de Barcelona, \\ Barcelona, Spain; and the Research Center for Alcoholic Liver and \\ Pancreatic Diseases, ${ }^{\ddagger}$ Keck School of Medicine of the University of \\ Southern California, Los Angeles, California
}

The mechanisms linking hepatocellular death, hepatic stellate cell (HSC) activation, and liver fibrosis are largely unknown. Here, we investigate whether acidic sphingomyelinase (ASMase), a known regulator of death receptor and stress-induced hepatocyte apoptosis, plays a role in liver fibrogenesis. We show that selective stimulation of ASMase (up to sixfold), but not neutral sphingomyelinase, occurs during the transdifferentiation/activation of primary mouse HSCs into myofibroblast-like cells, coinciding with cathepsin $B$ (CtsB) and D (CtsD) processing. ASMase inhibition or genetic down-regulation by small interfering RNA blunted CtsB/D processing, preventing the activation and proliferation of mouse and human HSCs (LX2 cells). In accordance, HSCs from heterozygous ASMase mice exhibited decreased CtsB/D processing, as well as lower levels of $\alpha$-smooth muscle actin expression and proliferation. Moreover, pharmacological CtsB inhibition reproduced the antagonism of ASMase in preventing the fibrogenic properties of HSCs, without affecting ASMase activity. Interestingly, liver fibrosis induced by bile duct ligation or carbon tetrachloride administration was reduced in heterozygous ASMase mice compared with that in wild-type animals, regardless of their sensitivity to liver injury in either model. To provide further evidence for the ASMase-CtsB pathway in hepatic fibrosis, liver samples from patients with nonalcoholic steatohepatitis were studied. CtsB and ASMase mRNA levels increased eight- and threefold, respectively, in patients compared with healthy controls. These findings illustrate a novel role of ASMase in HSC biology and liver fibrogenesis by regulating its downstream effectors CtsB/D. (Am J Pathol 2010, 177:1214-1224; DOI: 10.2353/ajpath.2010.091257)

Hepatic fibrosis is a wound-healing response of the liver to chronic injury and represents a common and complex clinical challenge worldwide. ${ }^{1-3}$ Liver fibrosis often reflects progressive liver disease caused by a variety of factors and etiologies including viral infection, cholestasis, alcoholic steatohepatitis, and nonalcoholic steatohepatitis (NASH). In developed countries, nonalcoholic fatty liver disease is associated with increasing rates of obesity and is currently one of the most common forms of chronic liver disease and a major cause of hepatic fibrosis. Nonalcoholic fatty liver disease, which encompasses a spectrum of liver diseases ranging from simple steatosis to NASH, is characterized by oxidative stress, inflammation, hepatocellular death, and fibrosis, which can further progress to cirrhosis and hepatocellular carcinoma. ${ }^{4-6}$ Thus, the number of individuals at risk for fibrosis and end-stage liver disease is rapidly expanding. ${ }^{7}$

In the liver, myofibroblasts are potentially derived from a number of cellular sources including activated hepatic stellate cells (HSCs), which mediate the fibrotic compo-

Supported by the Instituto de Salud Carlos III (grants PI070193 and PI0900056); the Plan Nacional de I+D, Spain (grants SAF2006-06780, SAF2005-06245, SAF2008-02199, 2009-11417); and the Research Center for Liver and Pancreatic Diseases, National Institute on Alcohol Abuse and Alcoholism, National Institutes of Health (grant P50-AA-11999). M.M. is an Institut d'investigacions Biomèdiques August Pi i Sunyer Investigator. A.M. is a recipient of a predoctoral fellowship from the Instituto de Salud Carlos III.

M.M. and J.C.F.-C. contributed equally to this work.

Accepted for publication May 6, 2010.

None of the authors disclosed any relevant financial relationships.

Supplemental material for this article can be found on http://ajp. amjpathol.org.

Address reprint requests to José C. Fernandez-Checa, Ph.D., or Montserrat Marí, Ph.D., Liver Unit, Hospital Clinic, C/Nillarroel 170, 08036-Barcelona, Spain. E-mail: checa229@yahoo.com and monmari@clinic.ub.es. 
nent of the wound-healing response to chronic injury. ${ }^{1,2,8}$ Under these conditions, HSCs undergo a phenotypic transformation from quiescent, nonproliferating, retinoidstoring cells, to a proliferating, matrix-producing phenotype similar to myofibroblasts responsible for the progression of liver fibrosis. ${ }^{9}{ }^{10}$ Despite increasing knowledge of the mechanisms that govern this so-called "activation," the treatment for advanced liver fibrosis is inefficient, and hence the development of novel antifibrotic targets and therapies is essential.

Membrane sphingolipids have been implicated in signal transduction cascades regulating proliferation, differentiation, and cell death. ${ }^{11,12}$ Among sphingolipids, ceramide has attracted considerable attention, given its central role in sphingolipid metabolism. Cellular ceramide levels increase in response to a variety of stimuli and agents from chemotherapy ${ }^{13}$ to death ligands, ${ }^{14-17}$ radiation, ${ }^{18}$ or viral/bacterial infections, ${ }^{19,20}$ because of the hydrolysis of sphingomyelin mainly by two specific phosphodiesterases named sphingomyelinases, a plasma membrane-bound neutral sphingomyelinase (NSMase) and an acidic SMase (ASMase). ${ }^{21-24}$ In particular, ASMase is expressed by almost any cell type and is mainly located at the endosomal/lysosomal compartment, although it has also been found at the plasma membrane in specific microdomains, where it serves as a signaling platform by cell surface receptors such as Fas. ${ }^{14-17}$ The placement of ASMase at the crossroad of vesicular trafficking and cellular signaling suggests that ASMase exerts important functions in signal transduction pathways. For instance, tumor necrosis factor (TNF) is a prominent prototype of an ASMase-activating cytokine that is central to the regulation of both the innate and the adaptive immune system as well as cell death. ${ }^{25,26} \mathrm{Al}$ though ASMase has been recognized to play a key role in the pathophysiology of different common diseases, ${ }^{27}$ its specific contribution to liver fibrosis has not been examined previously.

Moreover, the participation of cathepsin D (CtsD) as a target of ASMase-generated ceramide in endolysosomal compartments ${ }^{28,29}$ and the observation that cathepsin B (CtsB)-deficient hepatocytes are resistant to TNF-dependent cell death ${ }^{30}$ imply a functional relationship between ASMase and cathepsins, at least, in cell death regulation. However, this specific link has not been previously addressed in HSC biology and liver fibrosis. Because we have just uncovered a new function of CtsB and CtsD in mediating HSC activation and liver fibrosis, ${ }^{31}$ our aim was to investigate the role of ASMase in hepatic fibrogenesis. In this study, we tested whether ASMase contributes to the activation of mouse HSCs in vitro and to the development of fibrosis in vivo after bile duct ligation (BDL) or chronic carbon tetrachloride $\left(\mathrm{CCl}_{4}\right)$ injection. Here, we show that ASMase activity is induced during the transdifferentiation of HSCs into myofibroblasts, whereas HSC activation and proliferation are reduced by genetic or pharmacological antagonism of ASMase. Interestingly, heterozygous ASMase mice were resistant to BDL and chronic $\mathrm{CCl}_{4}$ administration-induced liver fibrosis compared with wild-type mice, even though their sensitivity to liver injury was markedly different with reduced liver damage in $\mathrm{ASMase}^{+/-}$mice after BDL but not after $\mathrm{CCl}_{4}$ administration. In addition, patients with NASH displayed enhanced levels of both CtsB and ASMase mRNA, underscoring the role of the ASMase-cathepsins axis in liver pathology and its relevance for future therapeutic approaches.

\section{Materials and Methods}

\section{Reagents}

The following reagents were from Invitrogen (Paisley, UK): Dulbecco's modified Eagle's medium, trypsinEDTA, penicillin-streptomycin, TRIzol, fetal bovine serum, HistoGrip, Opti-MEM, and Lipofectamine LTX with PLUS. All tissue culture ware was from Nunc (Roskilde, Denmark). The DAKO Biotin Blocking System, peroxidase substrate (diaminobenzidine), peroxidase buffer, and hematoxylin were from DAKO (Glostrup, Denmark). Aquatex was from Merck (Darmstadt, Germany). The ABC kit was from Vectastain (Burlingame, CA). Platelet-derived growth factor (PDGF)-BB was from PeproTech EC (London, UK). Proteinase inhibitors were from Roche (Madrid, Spain). The iScript One-Step RT-PCR kit with SYBR Green was from Bio-Rad (Hercules, CA). ECL Western Blotting Substrate was from Pierce (Thermo Fisher Scientific, Rockford, IL). Imipramine, amitriptyline, and Ca074Me were from Sigma-Aldrich (St. Louis, MO), and unless otherwise stated all other reagents were also from Sigma-Aldrich.

\section{Antibodies}

We used the following primary antibodies: rabbit polyclonal anti-cathepsin B from Upstate (Millipore, Billerica, MA), goat polyclonal anti-cathepsin D from Santa Cruz Biotechnology (Heidelberg, Germany), and monoclonal antibodies anti- $\alpha$-smooth muscle actin (SMA) and anti- $\beta$ actin from Sigma-Aldrich. Rabbit polyclonal anti- $\alpha$-SMA and rabbit polyclonal anti-myeloperoxidase were from Abcam (Cambridge, UK). ECL-labeled anti-mouse, antirabbit, and anti-goat antibodies were from Sigma-Aldrich.

\section{Mice and HSC Isolation}

Wild-type, heterozygous, and ASMase knockout mice (male, 8 to 10 weeks old, littermates) (C57BL/6 strain) were obtained by propagation of heterozygous breeding pairs (a generous gift from R. Kolesnick, Memorial SloanKettering Cancer Center, New York, NY, and E. Gulbins, University of Duisburg-Essen, Essen, Germany) and genotyped as described previously. ${ }^{26}$ All animals received humane care according to the criteria outlined in the Guide for the Care and Use of Laboratory Animals, published by the National Institutes of Health. ${ }^{32}$ HSCs were isolated by perfusion with collagenase-pronase and cultured as described previously. ${ }^{31}$ Cells were cultured in Dulbecco's modified Eagle's medium complemented with $10 \%$ fetal bovine serum and antibiotics at $37^{\circ} \mathrm{C}$ in a humidified atmosphere of $95 \%$ air and $5 \% \mathrm{CO}_{2}$. 


\section{In Vivo Liver Fibrogenesis}

To perform BDL, ASMase ${ }^{+/+}$and $\mathrm{ASMase}^{+/-}$mice were anesthetized by isoflurane inhalation. Under anesthesia, the peritoneal cavity was opened and the common bile duct was double-ligated with 5-0 sutures and cut between the ligatures. Controls underwent a sham operation that consisted of exposure but not ligation of the common bile duct. Animals were sacrificed 4 days after BDL, and liver and serum samples were collected for analyses. In another set of experiments, ASMase ${ }^{+/+}$and $\mathrm{ASMase}^{+/-}$mice were treated with $\mathrm{CCl}_{4}$ diluted in corn oil at a dose of $0.5 \mu$ of $\mathrm{CCl}_{4} / \mathrm{g}$ b.wt. by intraperitoneal injection twice a week, for 6 weeks. Control animals received vehicle alone.

\section{In Vitro Small Interfering RNA Transfection}

To silence ASMase expression, specific predesigned siRNAs for mouse ${ }^{33}$ were used for transfection using Lipofectamine LTX with PLUS following the manufacture's instruction as described previously. ${ }^{31}$ Cells were transfected 5 days after isolation and usually assayed 48 hours after small interfering (si) RNAs transfection.

\section{ASMase and NSMase Activities}

ASMase and NSMase activities from tissue or HSC lysates were determined using a fluorescent sphingomyelin analog (NBD-C6-sphingomyelin). Samples were incubated for 60 minutes at $37^{\circ} \mathrm{C}$ in incubation buffer containing $10 \mu \mathrm{mol} / \mathrm{L}$ NBD-C6-sphingomyelin (250 mmol/L sodium acetate and 0.1\% Triton X-100, pH:5.0, for ASMase analysis, and $20 \mathrm{mmol} / \mathrm{L}$ HEPES, $1 \mathrm{mmol} / \mathrm{L} \mathrm{MgCl}_{2}$, and $0.1 \%$ Triton X-100, pH 7.4, for NSMase). Lipids were extracted, dried under $\mathrm{N}_{2}$, and separated by thin-layer chromatography (chloroform-methanol-20\% $\mathrm{NH}_{4} \mathrm{OH}, 70: 30: 5, \mathrm{v} / \mathrm{v}$ ). NBDceramide was visualized under UV light, and images were acquired and analyzed using a Gel Doc XR System with Quantity One software (Bio-Rad).

\section{Real Time RT-PCR and Primer Sequences}

Total RNA from HSCs, mouse liver tissues, or LX2 cells was isolated with TRIzol reagent. Real-time RT-PCR was performed with an iScript One-Step RT-PCR Kit with SYBR Green following the manufacturer's instructions. The primers sequences used were the following: mouse $\alpha$-SMA, forward 5'-ACTACTGCCGAGCGTGAGAT-3' and reverse 5'-AAGGTAGACAGCGAAGCCAA-3' (GenBank accession no. NM_007392); mouse transforming growth factor- $\beta$, forward 5'-GTCAGACATTCGGGAAGCAG-3' and reverse 5'GCGTATCAGTGGGGGTCA-3' (GenBank accession no. NM_011577); mouse $\beta$-actin, forward 5'-GACGGCCAGGTCATCACTAT-3' and reverse 5'-CGGATGTCAACGTCACACTT-3' (GenBank accession no. NM_007393); mouse collagen type $1 \alpha 1$ (Col1A1), forward 5'-ACTTCAGCTTCCTGCCTCAG-3' and reverse 5'-TGACTCAGGCTCTTGAGGGT-3' (GenBank accession no. NM_007742); mouse TNF- $\alpha$, forward 5'-CTGAACTTCGGGGTGATCGGT-3' and reverse 5'-ACGTGGGCTACAGGCTTGTCA-3' (GenBank accession no. NM_013693); mouse 2',5' oligoadenylate synthetase 1, forward 5'-GACCTGCTGAAGGAGGTGAA-3' and reverse 5'-GGTACGCCCACTGATGAGAT-3' (GenBank accession no. AF466822); human $\beta$-actin, forward 5'-GATGAGATTGGCATGGCTTT-3' and reverse $5^{\prime}$ GAGAAGTGGGGTGGCTT-3' (GenBank accession no. NM_001101); and human $\alpha$-SMA, forward 5'-CCGACCGAATGCAGAAGG-3' and reverse 5'-ACAGAGTATTTGCGCTCCGGA-3' (GenBank accession no. NM_001613).

\section{CtsB Activity}

CtsB activity was assayed fluorimetrically with Z-Arg-Arg7-amido-4-methylcoumarin hydrochloride $(60 \mu \mathrm{mol} / \mathrm{L})$ at $\mathrm{pH} 7.4$ and $37^{\circ} \mathrm{C}$ as described previously. ${ }^{31}$

\section{$\left[{ }^{3} \mathrm{H}\right]$ Thymidine Incorporation}

Proliferation was estimated as the amount of $\left[{ }^{3} \mathrm{H}\right]$ thymidine incorporated into trichloroacetic acid-precipitable material as described previously. ${ }^{31}$

\section{SDS-Polyacrylamide Gel Electrophoresis and Immunoblot Analysis}

Lysates were prepared in radioimmunoprecipitation assay buffer (50 mmol/L Tris- $\mathrm{HCl}, \mathrm{pH} 7.4,150 \mathrm{mmol} / \mathrm{L} \mathrm{NaCl}$, $1 \%$ Nonidet P-40, $1 \mathrm{mmol} / \mathrm{L} \mathrm{Na} \mathrm{Na}_{4}, 1 \mathrm{mmol} / \mathrm{L}$ EDTA, $0.25 \%$ sodium deoxycholate, $0.1 \%$ SDS, and $1 \%$ Triton $\mathrm{X}-100$ plus proteinase inhibitors). Protein concentration was determined by the Bradford assay, and samples containing 10 to $30 \mu \mathrm{g}$ were separated by 8 to $10 \%$ SDS-polyacrylamide gel electrophoresis. Proteins were transferred to nitrocellulose membranes. After membranes were blocked in $8 \%$ nonfat milk in $20 \mathrm{mmol} / \mathrm{L}$ Tris- $\mathrm{HCl}, 150 \mathrm{mmol} / \mathrm{L} \mathrm{NaCl}$, and 1\% Tween 20 for 1 hour at room temperature, the membranes were incubated with the primary antibody overnight and developed with the ECL-peroxidase system.

\section{Determination of Hydroxyproline in Liver Tissue}

Hepatic hydroxyproline content was determined as described by Jamall et al. ${ }^{34}$ In brief, tissue samples were hydrolyzed in $6 \mathrm{~mol} / \mathrm{L} \mathrm{HCl}$ overnight at $100^{\circ} \mathrm{C}$ and purified 4-hydroxy-L-proline standards for 20 minutes at $120^{\circ} \mathrm{C}$. Free hydroxyproline content from each hydrolysate was oxidized with Chloramine-T. The addition of Ehrlich reagent resulted in the formation of a chromophore that was read at $550 \mathrm{~nm}$. Data were normalized to liver wet weight.

\section{Immunohistochemical Staining}

Paraffin molds containing liver sections were cut into $5-\mu \mathrm{m}$ sections and mounted on HistoGrip-coated slides. The sections were deparaffinized in xylene and dehydrated in a graded alcohol series. When necessary, endogenous peroxidase $\left(3 \% \mathrm{H}_{2} \mathrm{O}_{2}\right)$ and endogenous avidin 
and biotin were blocked. Slides were incubated with primary antibody overnight in a wet chamber at $4^{\circ} \mathrm{C}$. After a rinse with $1 \times$ PBS, the slides were incubated with a biotinylated antibody for 45 minutes in a wet chamber and developed with an ABC Kit with peroxidase substrate (diaminobenzidine) and peroxidase buffer. After the slides were rinsed with tap water, they were counterstained with hematoxylin and mounted with Aquatex.

\section{H\&E and Sirius Red Staining}

Livers were fixed, and sections of $7-\mu \mathrm{m}$ were routinely stained with $\mathrm{H} \& \mathrm{E}$ or with a $0.1 \%$ Sirius Red-picric solution following standard procedures. Bile-infarcted areas (the percentage of infarct area per high power field) were also quantified using digital image analysis software (ImageJ).

\section{Human NASH Cohort}

Patients with either borderline NASH $(n=14)$ or definite $\mathrm{NASH}(n=18)$, according to the Kleiner classification, ${ }^{35}$ sent to the hospital for bariatric surgery were included in the study. Patients underwent gastric bypass by laparoscopy and during the surgery procedure a liver biopsy was obtained using a Tru-Cut needle. Normal livers were obtained from optimal cadaveric liver donors $(n=3)$ or resection of liver metastases $(n=2)$. All controls had normal serum aminotransferase levels and normal liver histology. These subjects did not have a past history of liver disease, alcohol abuse, or metabolic syndrome. The study was approved by the ethics committee of the Hospital Clinic, and all patients gave informed consent.

\section{Hepatic Gene Expression Analysis in Human Samples}

Liver biopsy specimens were submerged in an RNA stabilization solution (RNAlater, Ambion, Applied Biosystems, Austin, TX) and stored at $-20^{\circ} \mathrm{C}$ until RNA extraction. Total RNA was extracted with TRIzol. Five hundred micrograms of total RNA were retrotranscribed with a high-capacity complementary DNA Archive Kit (Applied Biosystems). The genes selected were distributed into 384-well TaqMan Low Density Array cards, and samples were analyzed in quadruplicate using an ABI PRISM 7900 (Applied Biosystems). Predesigned TaqMan assays for target genes from Applied Biosystems were used (CtsB, Hs00157194_m1; ASMase, Hs00609415 m1; and 18S, Hs99999901_s1). Expression levels of target genes were normalized to expression of $18 \mathrm{~S}$ rRNA (endogenous gene). Gene expression values were calculated based on the $\Delta \Delta \mathrm{C}_{\mathrm{t}}$ method. ${ }^{36}$ The results are expressed as $2^{-\Delta \Delta C_{t}}$ referred as fold in relation to mean normal livers.

\section{Statistical Analysis}

All images display representative data from at least three independent observations. Statistical analyses were per- formed using Microsoft Excel software. The statistical significance of differences was determined using the unpaired, nonparametric Student's t-test.

\section{Results}

\section{In Vitro Activation of Mouse Primary HSCs Parallels ASMase Stimulation}

The culture of primary freshly isolated HSCs on plastic is known to cause transdifferentiation from a quiescent to a proliferating phenotype characterized by the activation of matrix-producing genes, which is the standard approach to analyze the activation of HSCs into myofibroblast-like cells. $^{2,8,9}$ Because this transdifferentiation is a central event in liver fibrogenesis, we first studied whether this process is accompanied by changes in ASMase activity. Thus, freshly prepared mouse primary HSCs were isolated to analyze ASMase and NSMase activity at different time points during transdifferentiation in culture. As shown in Figure 1A, ASMase activity, but not NSMase activity, increased more than fivefold from day 2 to day 9 of culture. In addition, the ASMase activity observed in primary mouse HSCs at day 9 was similar to the ASMase activity of LX2 cells $(620 \pm 85$ vs. $583 \pm 63$ arbitrary units/mg of protein), an immortalized human HSC cell line similar to human activated HSCs. ${ }^{37}$ This increase in ASMase activity paralleled the expression of $\alpha$-SMA, a reliable marker of the phenotypic transformation of HSCs into myofibroblast-like cells, ${ }^{2}$ which coincided with the levels of mature forms of CtsB and CtsD (Figure 1B). Thus, these findings indicate that in vitro activation of HSCs results in marked and selective stimulation of ASMase.

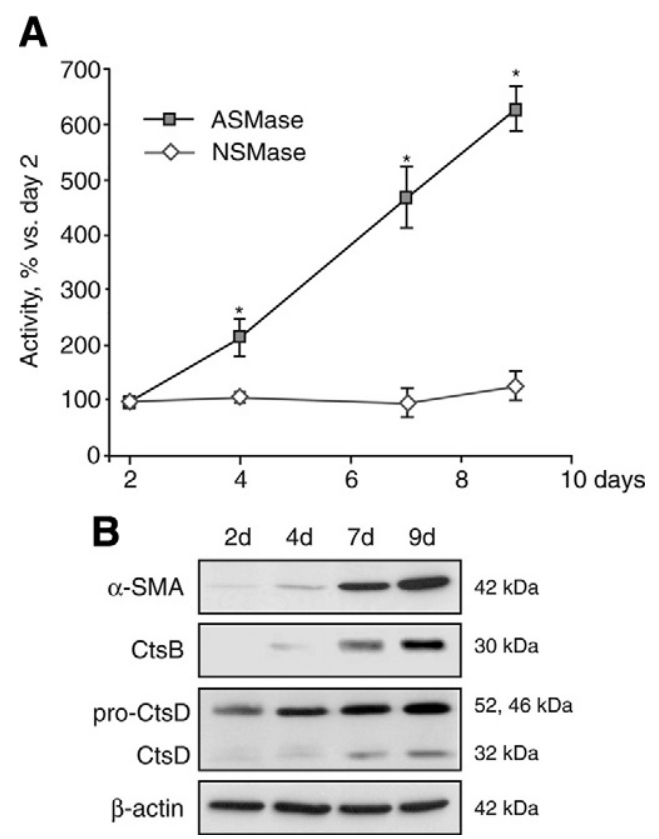

Figure 1. ASMase activity increases concordantly with CtsB and CtsD expression during HSC activation. A: Time-course of ASMase and NSMase activity during mouse HSC activation in culture. B: Time-course of $\alpha$-SMA, CtsB, and CtsD expression in primary mouse HSCs in in vitro culture from day two to day nine. Data are means $\pm \mathrm{SD} ; n=3 .{ }^{*} P \leq 0.05$ versus day 2 HSCs. 


\section{Pharmacological ASMase Inhibition or Genetic Silencing Blunts CtsB/D Processing and HSC Activation}

Given our previous results positioning CtsB/D as key players in liver fibrosis ${ }^{31}$ and because a functional relationship between ASMase and cathepsins has been established only in cell death regulation, ${ }^{28,29}$ we decided to evaluate whether the increased processing of CtsB and/or CtsD observed during HSC activation and recently associated with liver fibrogenesis, ${ }^{31}$ was dependent on ASMase. Therefore, ASMase was antagonized by two approaches, pharmacological inhibition and genetic down-regulation by siRNAs. Imipramine and amitriptyline are weak bases that induce the detachment of ASMase from the intralysosomal membrane, resulting in its subsequent functional inactivation. ${ }^{38}$ As shown in Figure $2 \mathrm{~A}$, both imipramine treatment and ASMase silencing by SiRNA resulted in a reduction in ASMase activity by $85 \pm 4$ and $48 \pm 12 \%$, respectively, without inducing an interferon response (not shown). The decline in ASMase activity, either by pharmacological inhibition or genetic silencing, resulted in decreased expression of CtsB/D processed forms (Figure 2, B and C). Moreover, the expression of $\alpha$-SMA was also reduced under these conditions (Figure 2, B and D), indicating an attenuation of the fibrogenic properties of HSCs after ASMase antagonism. The expression of Col1A1 or transforming growth
A
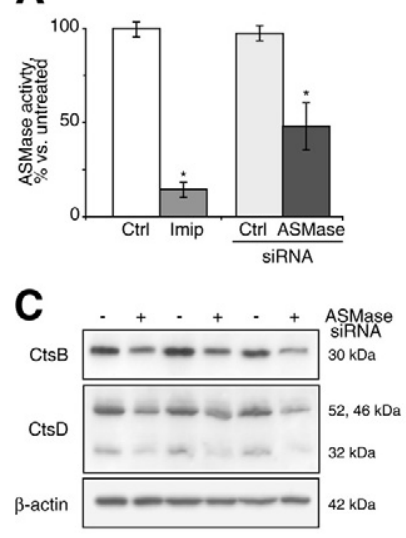

E

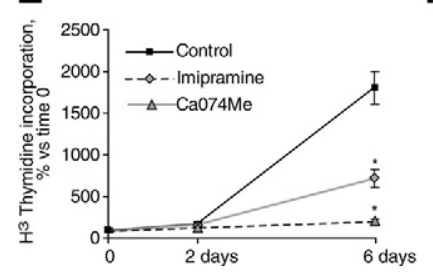

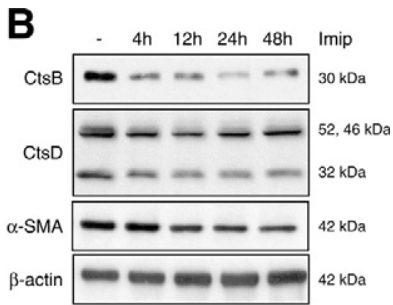

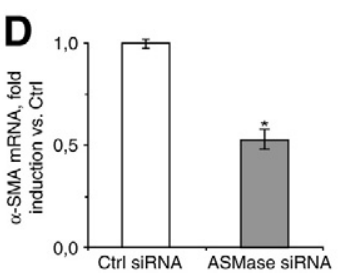

$\mathbf{F}$

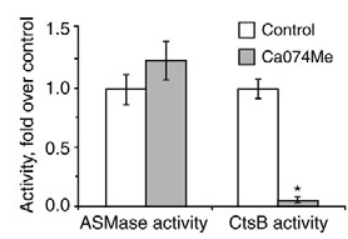

Figure 2. ASMase inhibition or SiRNA transfection reduces HSC activation and proliferation. A: ASMase activity after inhibition with imipramine (Imip, 25 $\mu \mathrm{mol} / \mathrm{L}$ ) for 24 hours or ASMase siRNA silencing for 48 hours, in cultured 7-days old mouse HSCs. CtsB and CtsD protein expression (B) and $\alpha$-SMA mRNA levels (D) after ASMase siRNA silencing for 48 hours, in cultured 7-days old mouse HSCs. C: Time course of CtsB, CtsD, and $\alpha$-SMA expression after ASMase inhibition (Imip, $25 \mu \mathrm{mol} / \mathrm{L}$ ) in 7-day-old HSCs. E: Time course of HSC proliferation in the presence of ASMase (Imip, $25 \mu \mathrm{mol} / \mathrm{L}$ ) or CtsB inhibitor (Ca074Me, $10 \mu \mathrm{mol} / \mathrm{L}$ ) in 7-day-old HSCs. F: ASMase and CtsB activity on inhibition of CtsB with Ca074Me (10 $\mu \mathrm{mol} / \mathrm{L}, 24$ hours) in 7-day-old HSCs. Data are means \pm SD; $n=4$. ${ }^{*} P \leq 0.05$ versus control HSCs. Ctrl, control. factor- $\beta$, however, was not significantly altered after ASMase inhibition or silencing (not shown), discarding the theory of direct participation of ASMase in either of these two pathways. On the other hand, complete CtsB inhibition, using Ca074Me, was able to significantly decrease transforming growth factor- $\beta$ expression (not shown), consistent with our previous observations. ${ }^{31}$ In addition, pharmacological inhibition of ASMase dramatically prevented HSC proliferation (Figure 2E). Even though cathepsins have previously been implicated in the degradation of PDGF $\beta$ R, ${ }^{39,40}$ we have not observed any alteration in the basal levels of PDGF $\beta$ R with inhibition of either ASMase or CstB (not shown). In line with this result, we have previously reported that although CtsB inhibition did not affect PDGF $\beta$ R levels, it impaired AKT phosphorylation after PDGF challenge, thus regulating HSC proliferation. ${ }^{31}$ To analyze the hierarchy between ASMase and cathepsins, we evaluated the effect of CtsB inhibition on ASMase levels. CtsB inhibition did not alter ASMase activity (Figure 2F) but was able to significantly blunt HSC proliferation (Figure 2E). Therefore, our results suggest that CtsB and CtsD processing depend on and are downstream of ASMase during the activation of HSCs into myofibroblasts.

\section{ASMase Inhibition Attenuates the Proliferation of Human HSCS}

To examine the relevance of the preceding findings in human fibrogenesis, we also evaluated the effect of ASMase inhibition in the human LX2 cell line. ${ }^{37}$ As shown in Figure 3A, ASMase inhibition by either imipramine or amitriptyline down-regulated the processing of CtsB and CtsD forms (Figure 3B), resulting in a striking decrease of $\alpha$-SMA expression at the protein and mRNA levels (Figure 3, B and
A

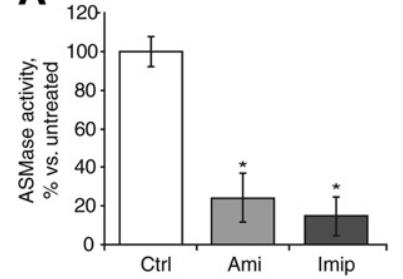

C

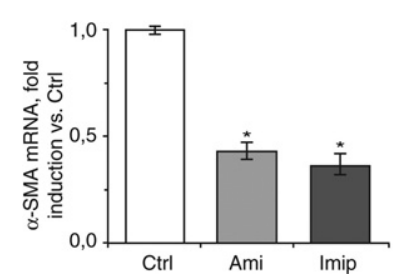

B

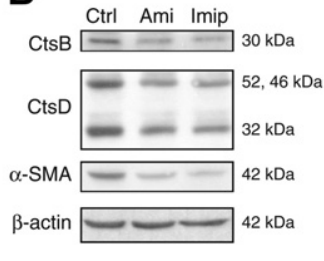

D

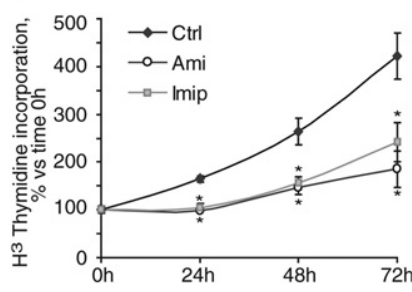

Figure 3. ASMase inhibition decreases CtsB, CtsD, and $\alpha$-SMA expression as well as proliferation in the human LX2 cell line. A: ASMase activity after inhibition with imipramine (Imip, $25 \mu \mathrm{mol} / \mathrm{L}$ ) or amitriptyline (Ami, 25 $\mu \mathrm{mol} / \mathrm{L}$ ) for 24 hours in LX2 cells. CtsB, CtsD, and $\alpha$-SMA protein expression (B) and $\alpha$-SMA mRNA levels (C) in LX2 cells after ASMase inhibition with imipramine $(25 \mu \mathrm{mol} / \mathrm{L})$ or amitriptyline $(25 \mu \mathrm{mol} / \mathrm{L})$ for 24 hours. D: Time course of HSC proliferation in LX2 cells in the presence ASMase inhibitors (imipramine, $25 \mu \mathrm{mol} / \mathrm{L}$; amitriptyline, $25 \mu \mathrm{mol} / \mathrm{L}$ ) for up to 72 hours. Data are means $\pm \mathrm{SD} ; n=3 .{ }^{*} P \leq 0.05$ versus control LX2 cells. Ctrl, control. 
C), followed by a reduction in LX2 proliferation (Figure 3D). Thus, in humans and rodents, the regulation of HSC activation and proliferation by ASMase-mediated CtsB/D processing may be of potential relevance in liver fibrosis.

\section{HSCs from Heterozygous ASMase Mice Exhibit Decreased ASMase Activity, CtsB/D Processing, and Proliferation}

Because pharmacological inhibition or siRNA-mediated reduction in ASMase expression decreased CtsB/D levels and HSC proliferation, we next evaluated the in vivo transdifferentiation process using HSCs from mice with a genetic reduction in ASMase. Indeed, HSCs from heterozygous ASMase mice displayed a 60 to $70 \%$ decrease in ASMase activity (Figure 4A). ASMase ${ }^{+/-}$HSCs exhibited low CtsB/CtsD and $\alpha$-SMA expression during in vitro activation (Figure 4B) compared with wild-type HSCs, consistent with the preceding data on ASMase antagonism (either pharmacological or by siRNA downregulation). Of note, the normal proliferation rate of heterozygous $\mathrm{ASMase}^{+/-} \mathrm{HSC}$ s was slower than that of wild-type HSCs (Figure 4C). Moreover, CtsB inhibition, using the specific CtsB inhibitor Ca074Me, down-regulated both the proliferation (Figure 4C) and activation (Figure 4D) of wild-type and heterozygous ASMase HSCs. These findings further strengthened the evidence for a role of ASMase in the regulation of $\mathrm{CtsB} / \mathrm{D}$ processing, which is critical for HSC activation and proliferation.

A

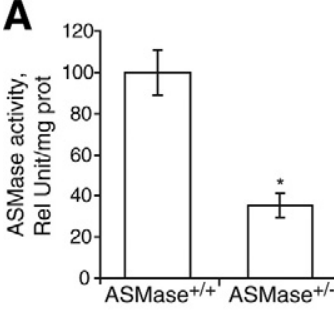

C

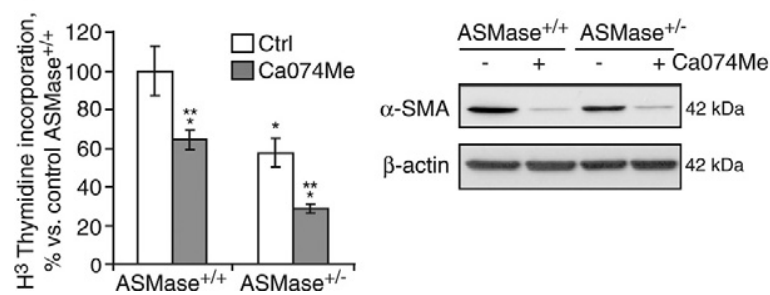

Figure 4. Heterozygous ASMase ${ }^{+/-}$HSCs exhibit decreased expression of CtsB, CtsD, and $\alpha$-SMA, and reduced proliferation in culture. A: ASMase activity in cultured 7-day-old wild-type or heterozygous ASMase ${ }^{+/-}$HSCs. B: Time course of CtsB, CtsD, and $\alpha$-SMA protein expression in wild-type and heterozygous ASMase ${ }^{+-}$HSCs. Proliferation rate $(\mathbf{C})$ and $\alpha$-SMA protein levels (D) after CtsB inhibition (Ca074Me, $10 \mu \mathrm{mol} / \mathrm{L}, 24$ hours) in wild-type or heterozygous ASMase ${ }^{+/-} 7$-day-old HSCs. In A data are means $\pm \mathrm{SD} ; n=$ 4. ${ }^{*} P \leq 0.01$ versus ASMase ${ }^{+/+}$HSCs. In $\mathbf{C}$ data are means $\pm \mathrm{SD} ; n=3 .{ }^{*} P \leq$ 0.05 versus ASMase ${ }^{+/+}$control HSCs; ${ }^{* *} P \leq 0.05$ versus respective controls (Ctrl). Rel Unit, relative units.

\section{Decreased Liver Damage and Fibrosis in Heterozygous ASMase After Bile Duct Ligation}

In view of the earlier findings indicating reduced fibrogenic potential of HSCs from heterozygous ASMase mice, we next assessed the in vivo susceptibility of wild-type and heterozygous ASMase mice to liver fibrosis. BDL is a well established model of liver fibrosis that is associated with intrahepatic cholestasis and bile acid accumulation. Because cholestasis is also known to induce hepatocyte damage, we used BDL in ASMase $^{+/-}$mice to examine the contribution of ASMase in BDL-mediated hepatic damage, HSC activation, and liver fibrosis. Based on our preceding findings, we would expect lower liver fibrosis after BDL in heterozygous ASMase mice compared with wild-type mice. However, for liver or hepatocyte damage, the anticipated effect of BDL on hepatocyte injury remained less predictable, based on recent findings reporting a critical role for Kupffer cell-derived ASMase in AKT activation of hepatocytes that is required for the survival and regenerative responses after BDL. ${ }^{41}$

Total hepatic extracts from heterozygous ASMase mice displayed a significant reduction in ASMase activity (50 to $60 \%$ decrease) compared with wild-type livers, in line with our observations during in vitro HSC activation (Figure 4A). Serum alanine aminotransferase (ALT), as an indicator of liver damage, was markedly increased in wild-type mice after BDL for 4 days. However, unexpectedly, ALT levels were significantly reduced in heterozygous ASMase BDL mice compared with wild-type BDL mice (Figure 5A). These observations were further validated by terminal deoxynucleotidyl transferase dUTP nick-end labeling staining of liver sections, revealing severe parenchymal damage after BDL in wild-type but not in heterozygous ASMase livers (Supplemental Figure 1, see http://ajp.amjpathol.org), thus indicating a novel role for ASMase in cholestasis-induced hepatocellular death. To analyze the fibrogenic process, levels of hydroxyproline (Figure 5B), a major component of collagen, and Col1A1 mRNA (Figure 5C) were analyzed. Both parameters were significantly enhanced in wild-type BDL livers but reduced in heterozygous ASMase BDL livers. Bile infarcts are confluent foci of degenerated hepatocytes due to bile acid toxicity and are a prominent feature of liver injury in the BDL mouse. The number of bile infarcts in the liver was quantified by conventional H\&E staining. Numerous bile infarcts per high power field area were observed in the wild-type BDL model; however, the occurrence of bile infarcts was scarce in heterozygous BDL livers (Figure 5D). Histopathological examination of liver tissue (Figure 5E) demonstrated cholestatic hepatitis, with widespread incidence of bile infarcts and hepatocellular damage in wild-type BDL mice. In contrast, heterozygous ASMase mice displayed minor liver injury. Moreover, when the appearance of collagen was analyzed by Sirius Red staining, the presence of collagen fibers was only observed in wild-type BDL mice but not in ASMase $^{+/-}$mice (Figure 5E). This enhanced liver damage and the presence of bile infarcts in wild-type BDL mice occurred despite expression of TNF in heterozy- 
A

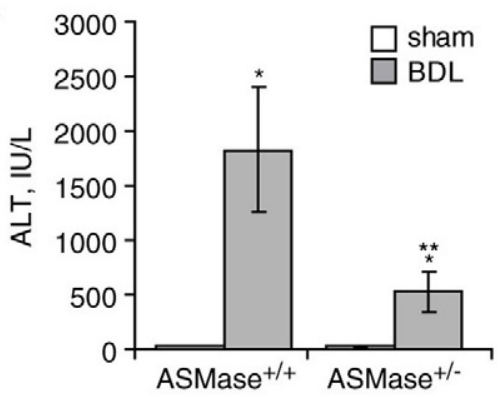

C

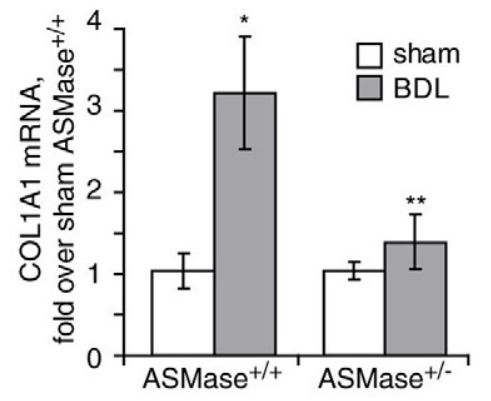

E

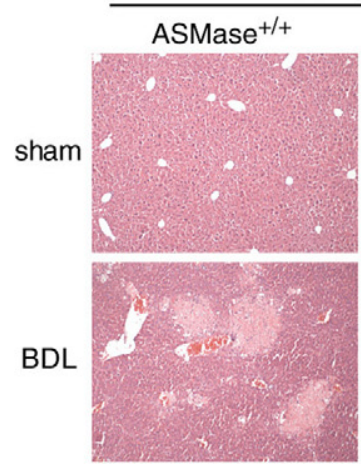

B

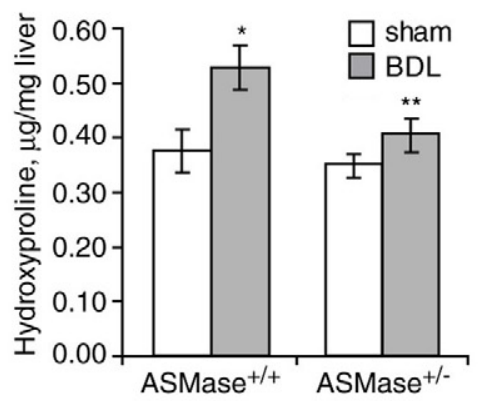

D

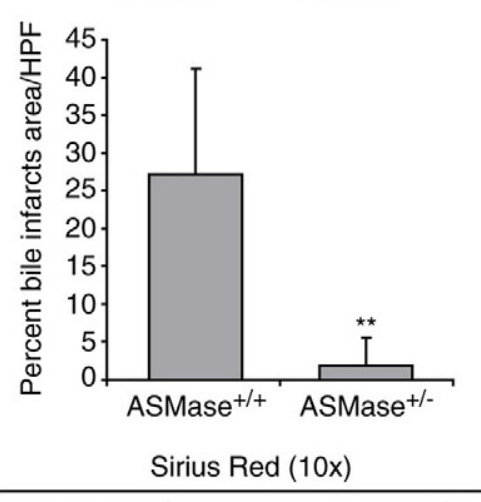

Figure 5. ASMase $^{+/-}$mice display decreased liver damage and fibrosis compared with wild-type mice when subjected to BDL. Serum ALT (A), hydroxyproline levels (B), Col1A1 mRNA expression $(\mathbf{C})$, percentage of bile infarcted area per high power field (HPF) (D), H\&E and Sirius Red staining of liver samples (E), and TNF mRNA expression levels (F) were determined 4 days after BDI in ASMase ${ }^{+/+}$and ASMase ${ }^{+/-} ; n=5$ animals per group. In $\mathbf{A}, \mathbf{B}, \mathbf{C}$, and $\mathbf{F},{ }^{*} P \leq 0.05$ versus sham mice. In $\mathbf{A}, \mathbf{B}, \mathbf{C}$, and $\mathbf{D},{ }^{* * *} P \leq 0.05$ versus ASMase $^{+/+}$BDL mice.

gous ASMase BDL mice similar to that in wild-type mice (Figure 5F). Moreover, the total pool of bile acids in liver extracts after BDL did not differ between wild-type and heterozygous ASMase (not shown), indicating that the reduction in liver fibrosis is not a consequence of lower cholestasis. These findings underscore the relevance of ASMase expression in controlling both hepatocellular damage and liver fibrosis in mice during cholestasis.

\section{Similar Liver Damage but Reduced Fibrosis in Heterozygous ASMase Mice after $\mathrm{CCl}_{4}$} Administration

We next assessed the contribution of ASMase in an experimental model that includes significant hepatocellular injury followed by fibrosis, using the in vivo model of $\mathrm{CCl}_{4}$ administration, a well established model of liver injury and liver fibrosis. $\mathrm{CCl}_{4}$ administered twice a week for 6 weeks to ASMase $^{+/+}$and ASMase ${ }^{+/-}$mice increased serum ALT to a similar level in wild-type and heterozygous ASMase mice (Figure 6A). Hepatocellular damage was also assessed by terminal deoxynucleotidyl transferase dUTP nick-end labeling staining of liver sections, revealing comparable injury in wild-type and ASMase ${ }^{+/-}$livers (Supplemental Figure 1, see $h$ ttp://ajp.amjpathol.org). However, regardless of the extent of liver damage, ASMase ${ }^{+/-}$mice exhibited significantly decreased liver fibrosis, detected by hydroxyproline levels (Figure 6B), Col1A1 mRNA expression (Figure 6C), immunostaining of $\alpha$-SMA-positive cells (Figure 6D), and Sirius Red staining (Figure 6E). Thus, unlike the BDL model, these findings underscore a hepatocellular damage-independent role of ASMase in liver fibrosis.

\section{Increased Expression of ASMase and CtsB in Livers from Patients with NASH}

Finally, to explore whether the observed effects in HSCs and mice may be of potential relevance in human disease, we analyzed the mRNA expression of ASMase and CtsB in patients with NASH at different stages. As shown in Figure 7A, ASMase mRNA expression was significantly increased in a group of 18 patients with NASH with a Kleiner score of 5 to 6 , indicative of definitive $\mathrm{NASH}^{35}$ based on the assessment of the range of histological features of human NASH. However, in patients with a score of 3 to 4 and classified as having borderline NASH 
A

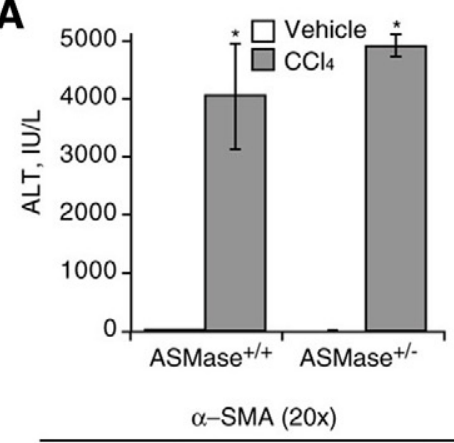

D

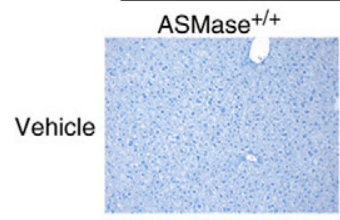

$+\mathrm{CCl}_{4}$
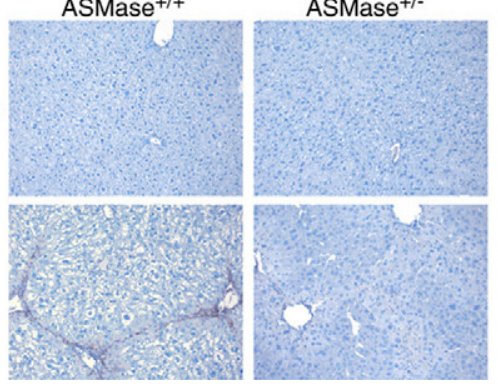

B

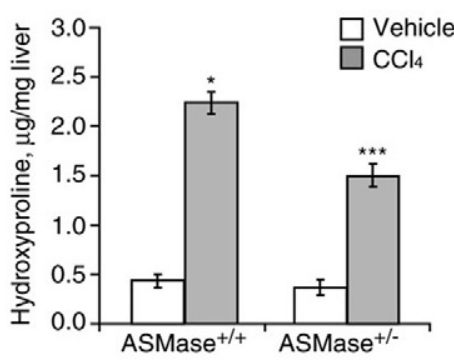

E

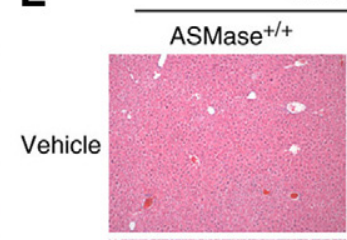

$H \& E(10 x)$

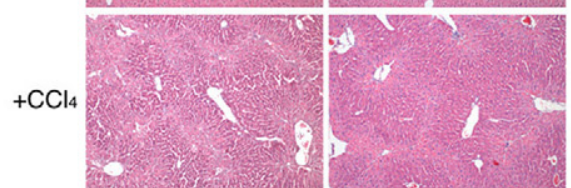

C

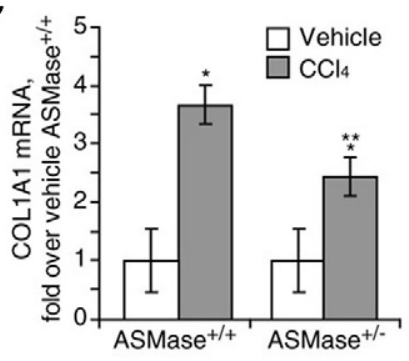

Figure 6. ASMase ${ }^{+/-}$mice display similar liver damage but decreased fibrosis after $\mathrm{CCl}_{4}$ injection. Six weeks after initial CCl4 challenge, we determined serum ALT (A), hydroxyproline levels (B), Col1A1 mRNA expression (C), $\alpha$-SMA immunostaining (D), and H\&E and Sirius Red staining of liver samples (E) from ASMase $^{+/+}$and ASMase ${ }^{+/-}$mice. Data are means \pm SEM; $n=5$ animals per group. In $\mathbf{A}, \mathbf{B}$, and $\mathbf{C},{ }^{*} P \leq 0.05$ versus vehicle-treated mice. In $\mathbf{B}$ and $\mathbf{C}$, ${ }^{* *} P \leq$ 0.05 versus ASMase ${ }^{+/+}+\mathrm{CCl}_{4}$-treated mice.

$(n=14)$, mean mRNA expression of ASMase was increased compared with that of control patients, but it did not reach statistical significance. Of note, both groups of patients with $\mathrm{NASH}$ exhibited significantly enhanced CtsB mRNA expression, with a higher mean value observed in those patients who were classified as having definitive NASH (Figure 7B). In addition, although laboratory test abnormalities may be suggestive of $\mathrm{NASH}$, histological evaluation remains the only way to accurately stage NASH. Even though the Kleiner activity score does not include histological evaluation of fibrosis, $71 \%$ (10 of 14) and $91.44 \%$ (17 of 18 ) of our patients with borderline or definite $\mathrm{NASH}$, respectively, had some degree of hepatic fibrosis, none of them reaching the cirrhosis stage.
A

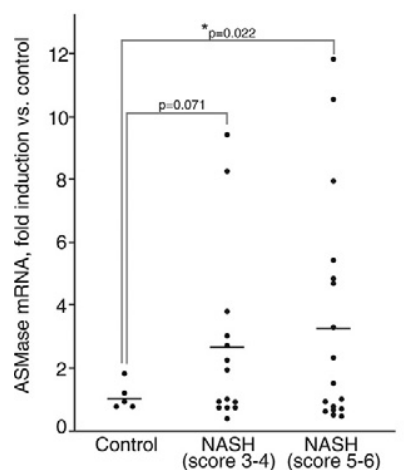

\section{B}

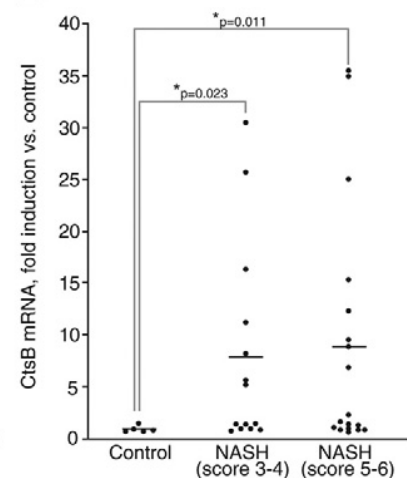

Figure 7. ASMase and CtsB expression are increased in patients with NASH Liver samples from control or NASH subjects were processed for RNA isolation to determine the expression of ASMase mRNA (A) and CtsB mRNA (B). Patients with NASH were separated in two groups: those with a score of 3 to 4 or borderline NASH, and those with a score of 5 to 6 or definite NASH, according to the Kleiner classification. $P$ values are indicated in the graph.
Moreover, the presence of fibrosis is an unequivocal indicator of progressive liver disease. In fact, despite the classification established by our pathologists, the clinical data of the patients with borderline or definite $\mathrm{NASH}$, summarized in Table 1, did not reveal major significant differences among groups. In all, our findings indicate that the elevation of ASMase and CtsB levels may be of relevance in patients with $\mathrm{NASH}$, including those at an initial stage of the disease. As a caveat, the only information we have available regarding CtsB and ASMase in these sets of patients is their mRNA expression, and hence we cannot directly determine that this mRNA increase is exclusively due to fibrosis. Other features of $\mathrm{NASH}$, such as hepatocellular apoptosis, could contribute to this outcome because both CtsB and ASMase have also been associated with apoptosis. ${ }^{12,25,27,29,30}$ Moreover, although in the $\mathrm{CCl}_{4}$ model of liver fibrosis we have previously observed that the expression of CtsB was confined to activated HSCs and not in parenchymal cells, ${ }^{31}$ we cannot reach such a conclusion in the present human cohort, which will need further study. Therefore, the present level of analyses suggests that certain patients with histological NASH have abnormal expression of hepatic ASMase and CtsB mRNA.

\section{Discussion}

Using in vitro HSCs and in vivo models of liver fibrosis, we describe a previously unknown role for ASMase in HSC activation and liver fibrosis and establish a causal relationship between ASMase and cathepsins in HSC biology. Up-regulation of ASMase has been described in 
Table 1. Clinical Data of Patients with Borderline or Definite NASH

\begin{tabular}{|c|c|c|c|}
\hline & Borderline NASH $(n=14)$ & Definite NASH $(n=18)$ & $P$ \\
\hline Age (years) & $44.07 \pm 3.31$ & $49.5 \pm 2.16$ & NS \\
\hline Female (\%) & 42.86 & 66.66 & NS \\
\hline BMI $\left(\mathrm{kg} / \mathrm{m}^{2}\right)$ & $47.56 \pm 1.94$ & $50.49 \pm 1.86$ & NS \\
\hline Waist circumference (cm) & $142.19 \pm 4.17$ & $138.08 \pm 5.01$ & NS \\
\hline Diabetes (\%) & 35.71 & 50 & NS \\
\hline Hypertension (\%) & 64.28 & 77.77 & NS \\
\hline Metabolic syndrome & 71.43 & 88.88 & NS \\
\hline Glucose (mg/dl) & $121 \pm 12$ & $133 \pm 13$ & NS \\
\hline HOMA & $12.82 \pm 2.82$ & $11.93 \pm 1.55$ & NS \\
\hline Cholesterol (mg/dl) & $184.57 \pm 8.56$ & $203.39 \pm 7.87$ & NS \\
\hline Triglycerides (mg/dl) & $137.85 \pm 11.34$ & $147 \pm 15.68$ & NS \\
\hline GGT $(\mathrm{U} / \mathrm{L})$ & $38 \pm 4$ & $51 \pm 9$ & 0.047 \\
\hline ALT (U/L) & $42 \pm 5$ & $62 \pm 7$ & NS \\
\hline AST (U/L) & $33 \pm 3$ & $41 \pm 4$ & 0.002 \\
\hline Bilirubin (mg/dl) & $0.57 \pm 0.06$ & $0.58 \pm 0.05$ & NS \\
\hline Platelet count $\left(\times 10^{9}\right)$ & $296 \pm 15$ & $297 \pm 17$ & NS \\
\hline Fibrosis, stage 1 to $3(\%)$ & 71 & 91.44 & NS \\
\hline
\end{tabular}

Data are means \pm SE or \%.

NS, not significant; HOMA, homeostasis model assessment; GGT, $\gamma$-glutamyl transferase; ALT, alanine transferase; AST, aspartate aminotransferase.

similar contexts such as differentiation of monocytes to macrophages ${ }^{42}$ and in drug-induced differentiation of leukemia cells. ${ }^{43}$ Although the participation of ceramide generated by ASMase in multiple signaling cellular processes of physiological or pathological impact, such as radiation-induced apoptosis, ${ }^{44}$ Wilson disease, ${ }^{45}$ fulminant hepatitis, ${ }^{25}$ cystic fibrosis, ${ }^{46}$ Pseudomonas aeruginosa infection, ${ }^{19}$ or emphysema, ${ }^{47}$ and in other common diseases ${ }^{27}$ has been reported, the role of ASMase in HSC activation and liver fibrogenesis had not been fully characterized so far. Recent observations suggest that the activation of rat HSCs by hydrophobic bile acids is mediated by NAPDH oxidases in an ASMase- and protein kinase $\mathrm{C} \zeta$-dependent manner. ${ }^{48}$ However, the contribution of ASMase per se to the activation of HSCs and liver fibrosis was not specifically addressed. Our results indicate that pharmacological inhibition or silencing of ASMase decreases the profibrogenic phenotype of HSCs, further supporting the participation of ASMase in HSC transdifferentiation. Moreover, the involvement of ASMase in HSC activation and proliferation was also validated in LX2 cells, a well established human HSC cell line, indicating that the regulation of HSC activation by ASMase may have potential relevance in human liver fibrosis.

Most previous studies linked ASMase-derived ceramide to cell death, even though the direct targets of ASMase-derived ceramide are still poorly defined. ${ }^{12}$ For instance, in liver injury, ASMase activation has been shown to promote hepatocyte apoptosis mediated by TNF $^{25,26}$ or hepatic ischemia-reperfusion ${ }^{33}$ or in Wilson's disease. ${ }^{45}$ Our findings add another facet of ASMase in liver pathobiology: ASMase promotes HSC activation and liver fibrosis by regulating $\mathrm{CtsB} / \mathrm{D}$ processing. Although cathepsins and possibly other acidic proteases participate in self-sustained processing events, ${ }^{31}$ our data indicate that ASMase is essential for CtsB/D processing, but not vice versa, suggesting that ASMase is upstream of both CtsB and CtsD.
After the encouraging results observed with antagonism of ASMase by pharmacological inhibition or siRNA silencing, we used a genetic model of ASMase deficiency. Surprisingly, complete loss of ASMase activity in the ASMase knockout mouse reflected by undetectable activity of ASMase resulted in an enhanced basal level of CtsB and CtsD processing (not shown) compared with that of either wild-type or ASMase ${ }^{+/-}$mice (which exhibit a partial reduction in ASMase as shown in Figure 4A). Because we observed that ASMase is critical for the proteolytic processing of both CtsB and CtsD, these findings with the knockout mice indicate that the total loss of ASMase leads to a compensatory gain of function of cathepsins, which in turn, exacerbates in vivo fibrosis after carbon tetrachloride administration (not shown). These observations are intriguing and merit further assessment. Total loss of ASMase is pathological and serves as a model for Niemann-Pick type A disease. Although Niemann-Pick type A disease is mainly characterized by rapid neurodegeneration, these patients also often exhibit liver deterioration, with some patients dying of liver failure within 3 years before the onset of the neurological symptoms. ${ }^{49}$ Interestingly, introducing a partially functional gene ( $\sim 8 \%$ residual ASMase activity) in mice onto the complete ASMase knockout background prevented the neurological phenotype, and the mice exhibited a normal lifespan. ${ }^{50}$ Hence, these observations provide evidence that very low levels of ASMase activity are sufficient to eliminate the pathological state induced by complete ASMase deficiency, illustrating the paradoxical role of ASMase in pathophysiology. ${ }^{49}$

In sharp contrast with the observations with ASMase knockout mice, our data with heterozygous ASMase clearly indicate a vital role for ASMase in the regulation of HSC activation and proliferation in vitro as well as liver fibrogenesis in vivo by modulating the processing of $\mathrm{CtsB}$ and $\mathrm{Cts}$. Although the role of ASMase in in vivo liver fibrosis induced by $\mathrm{BDL}$ and $\mathrm{CCl}_{4}$ is consistent with our in vitro observations, the impact of ASMase on hepatocyte 
damage caused by cholestasis is unexpected and deserves further comment. The extent of liver damage caused by BDL, a model of liver injury mediated predominantly by accumulation of toxic bile acids, was extensive in wild-type mice, accompanied by inflammatory cells infiltration, features that were markedly reduced in heterozygous ASMase mice. These findings point to a novel role of ASMase in cholestasis-mediated hepatocellular injury, which deserves further study to determine the underlying mechanisms. Recently, Osawa et al, ${ }^{41}$ assessed the specific role of ASMase in Kupffer cells during BDL-induced cholestasis. Somewhat contrary to our observations, silencing ASMase in Kupffer cells but not in hepatocytes impaired BDL-mediated AKT activation in hepatocytes, which was essential for cell survival and liver regeneration. On the other hand, deoxycholic acid has been reported to activate c-Jun $\mathrm{NH}_{2}$-terminal kinase, a stress-activated kinase that regulates cell death, by a mechanism involving the ASMase/Fas receptor. ${ }^{51}$ Thus, although it was out of the scope of the study, our observations point to a novel role for ASMase in BDL-induced hepatocyte injury.

Paralleling the resistance of heterozygous ASMase mice to hepatocyte damage caused by BDL, collagen synthesis and liver fibrosis were significantly reduced, in line with the notion that hepatocellular damage is an important trigger of HSC activation and hence fibrosis fostered in previous studies. ${ }^{52}$ In contrast, in the experimental model of liver fibrosis by chronic $\mathrm{CCl}_{4}$ administration, heterozygous ASMase mice display liver damage similar to that of wild-type mice but reduced fibrosis, thus strengthening the evidence for a critical contribution of ASMase in HSC activation, independent of hepatocellular damage.

Overall, our findings indicate a dual function of ASMase in liver fibrogenesis with a direct role primarily determined by the regulation of HSC activation/proliferation via CtsB/D processing and an indirect role by modulating hepatocyte susceptibility to apoptosis induced by cholestasis and perhaps other forms of liver injury. In view of our findings indicating that ASMase is upstream of CtsB in HSCs and the critical role of CtsB in BDLinduced hepatocyte apoptosis, ${ }^{52}$ the functional relationship between ASMase and CtsB in the hepatocellular susceptibility to BDL deserves further investigation. Given the role of ASMase in regulating hepatocellular injury shown in previous studies ${ }^{25,26}$ and liver fibrosis in the present study, this enzyme may be an attractive target for chronic liver diseases. Therefore, a therapy based on ASMase antagonism may induce a dual beneficial effect, on the one hand by limiting ASMase activity in hepatocytes and thus protecting them from hepatocellular damage, and on the other hand by interfering with HSC activation and reducing liver fibrosis.

Finally, our findings indicate that patients with NASH exhibit increased expression of ASMase and CtsB mRNA levels compared with healthy controls. However, we cannot rule out the contribution of other features of $\mathrm{NASH}$ apart from fibrosis, such as apoptosis, to this outcome. Therefore, further work is needed to identify the cell population of enhanced CtsB and ASMase expression and mechanisms responsible for these events in human livers and validate whether the increase in ASMase/CtsB mRNA occurs in liver fibrosis of different etiology such as chronic viral hepatitis.

\section{Acknowledgment}

The technical assistance of Susana Nuñez is highly appreciated.

\section{References}

1. Iredale JP: Models of liver fibrosis: exploring the dynamic nature of inflammation and repair in a solid organ. J Clin Invest 2007, 117:539-548

2. Friedman SL: Hepatic stellate cells: protean, multifunctional, and enigmatic cells of the liver. Physiol Rev 2008, 88:125-172

3. Tsukada S, Parsons CJ, Rippe RA: Mechanisms of liver fibrosis. Clin Chim Acta 2006, 364:33-60

4. Brunt EM: Nonalcoholic steatohepatitis. Semin Liver Dis 2004, 24:3-20

5. Bugianesi E, Leone N, Vanni E: Expanding the natural history of nonalcoholic steatohepatitis: from cryptogenic cirrhosis to hepatocellular carcinoma. Gastroenterology 2002, 123:134-140

6. Clark JM, Diehl AM: Nonalcoholic fatty liver disease: an underrecog nized cause of cryptogenic cirrhosis. JAMA 2003, 289:3000-3004

7. Erickson SK: Nonalcoholic fatty liver disease. J Lipid Res 2009 50:S412-S416

8. Bataller R, Brenner DA: Liver fibrosis. J Clin Invest 2005, 115:209-218

9. Gressner AM: Transdifferentiation of hepatic stellate cells (Ito cells) to myofibroblasts: a key event in hepatic fibrogenesis. Kidney Int 1996, 54:S39-S45

10. Kisseleva T, Brenner DA: Hepatic stellate cells and the reversal of fibrosis. J Gastroenterol Hepatol 2006, 21:S84-S87

11. Hannun YA, Obeid LM: Principles of bioactive lipid signalling: lessons from sphingolipids. Nat Rev Mol Cell Biol 2008, 9:139-150

12. Morales A, Lee H, Goñi FM, Kolesnick R, Fernández-Checa JC: Sphingolipids and cell death. Apoptosis 2007, 12:923-939

13. Liu YY, Yu JY, Yin D, Patwardhan GA, Gupta V, Hirabayashi Y, Holleran WM, Giuliano AE, Jazwinski SM, Gouaze-Andersson V, Consoli DP, Cabot MC: A role for ceramide in driving cancer cell resistance to doxorubicin. FASEB J 2008, 22:2541-2551

14. Grassmé $H$, Jekle A, Riehle A, Schwarz H, Berger J, Sandhoff K Kolesnick R, Gulbins E: CD95 signaling via ceramide-rich membrane rafts. J Biol Chem 2001, 276:20589-20596

15. Grassmé H, Cremesti A, Kolesnick R, Gulbins E: Ceramide-mediated clustering is required for CD95-DISC formation. Oncogene 2003, 22:5457-5470

16. Krönke M: Biophysics of ceramide signaling: interaction with proteins and phase transition of membranes. Chem Phys Lipids 1999, 101:109-121

17. Schuchman EH, Suchi M, Takahashi T, Sandhoff K, Desnick RJ: Human acid sphingomyelinase. Isolation, nucleotide sequence and expression of the full-length and alternatively spliced cDNAs. J Biol Chem 1991, 266:8531-8539

18. Smith EL, Schuchman EH: Acid sphingomyelinase overexpression enhances the antineoplastic effects of irradiation in vitro and in vivo. Mol Ther 2008, 16:1565-1571

19. Grassmé H, Jendrossek V, Riehle A, von Kürthy G, Berger J, Schwarz H, Weller M, Kolesnick R, Gulbins E: Host defense against Pseudomonas aeruginosa requires ceramide-rich membrane rafts. Nat Med 2003, 9:322-330

20. Becker KA, Gellhaus A, Winterhager E, Gulbins E: Ceramide-enriched membrane domains in infectious biology and development. Subcell Biochem 2008, 49:523-538

21. Schütze S, Potthoff K, Machleidt T, Berkovic D, Wiegmann K, Krönke M: TNF activates NF- $\kappa$ B by phosphatidylcholine-specific phospholipase C-induced "acidic" sphingomyelin breakdown. Cell 1992, 71:765-776

22. Wiegmann K, Schütze $S$, Machleidt T, Witte D, Krönke M: Functional dichotomy of neutral and acidic sphingomyelinases in tumor necrosis factor signaling. Cell 1994, 78:1005-1015 
23. Cifone MG, Roncaioli P, De Maria R, Camarda G, Santoni A, Ruberti G, Testi R: Multiple pathways originate at the Fas/APO-1 (CD95) receptor: sequential involvement of phosphatidylcholine-specific phospholipase $\mathrm{C}$ and acidic sphingomyelinase in the propagation of the apoptotic signal. EMBO J 1995, 14:5859-5868

24. Liu P, Anderson RG: Compartmentalized production of ceramide at the cell surface. J Biol Chem 1995, 270:27179-27185

25. García-Ruiz C, Colell A, Marí M, Morales A, Calvo M, Enrich C, Fernández-Checa JC: Defective TNF- $\alpha$-mediated hepatocellular apoptosis and liver damage in acidic sphingomyelinase knockout mice. J Clin Invest 2003, 111:197-208

26. Marí M, Colell A, Morales A, Pañeda C, Varela-Nieto I, García-Ruiz C, Fernández-Checa JC: Acidic sphingomyelinase downregulates the liver-specific methionine adenosyltransferase $1 \mathrm{~A}$, contributing to tumor necrosis factor-induced lethal hepatitis. J Clin Invest 2004, 113:895-904

27. Smith EL, Schuchman EH: The unexpected role of acid sphingomyelinase in cell death and the pathophysiology of common diseases. FASEB J 2008, 22:3419-3431

28. Heinrich M, Wickel M, Schneider-Brachert W, Sandberg C, Gahr J, Schwandner R, Weber T, Saftig P, Peters C, Brunner J, Krönke M, Schütze S: Cathepsin D targeted by acid sphingomyelinase-derived ceramide. EMBO J 1999, 8:5252-5263

29. Heinrich M, Neumeyer J, Jakob M, Hallas C, Tchikov V, WinotoMorbach S, Wickel M, Schneider-Brachert W, Trauzold A, Hethke A, Schütze S: Cathepsin D links TNF-induced acid sphingomyelinase to Bid-mediated caspase-9 and -3 activation. Cell Death Differ 2004, 11:550-563

30. Guicciardi ME, Deussing J, Miyoshi H, Bronk SF, Svingen PA, Peters C, Kaufmann SH, Gores GJ: Cathepsin B contributes to TNF- $\alpha$ mediated hepatocyte apoptosis by promoting mitochondrial release of cytochrome c. J Clin Invest 2000, 106:1127-1137

31. Moles A, Tarrats N, Fernández-Checa JC, Marí M: Cathepsins B and $D$ drive hepatic stellate cell proliferation and promote their fibrogenic potential. Hepatology 2009, 49:1297-1307

32. Institute of Laboratory Animal Resources: Guide for the Care and Use of Laboratory Animals, 7th ed. Washington, DC, Institute of Laboratory Animal Resources, Commission on Life Sciences, National Research Council, 1996

33. Llacuna L, Marí M, Garcia-Ruiz C, Fernández-Checa JC, Morales A: Critical role of acidic sphingomyelinase in murine hepatic ischemiareperfusion injury. Hepatology 2006, 44:561-572

34. Jamall IS, Finelli VN, Que Hee SS: A simple method to determine nanogram levels of 4-hydroxyproline in biological tissues. Anal Biochem 1981, 112:70-75

35. Kleiner DE, Brunt EM, Van Natta M, Behling C, Contos MJ, Cummings OW, Ferrell LD, Liu YC, Torbenson MS, Unalp-Arida A, Yeh M, McCullough AJ, Sanyal AJ: Nonalcoholic Steatohepatitis Clinical Research Network. Design and validation of a histological scoring system for nonalcoholic fatty liver disease. Hepatology 2005, 41:1313-1321

36. Livak KJ, Schmittgen TD: Analysis of relative gene expression data using real-time quantitative PCR and the $2^{-\Delta \Delta \mathrm{C}_{\mathrm{t}}}$. Method Methods 2001, 5:402-408

37. Xu L, Hui AY, Albanis E, Arthur MJ, O'Byrne SM, Blaner WS, Mukherjee P, Friedman SL, Eng FJ: Human hepatic stellate cell lines. LX-1 and LX-2: new tools for analysis of hepatic fibrosis. Gut 2005, 54:142-151

38. Kornhuber J, Tripal P, Reichel M, Terfloth L, Bleich S, Wiltfang J, Gulbins E: Identification of new functional inhibitors of acid sphingomyelinase using a structure-property-activity relation model. J Med Chem 2008, 51:219-237

39. Takashima T, Kawada N, Maeda N, Okuyama H, Uyama N, Seki S,
Arakawa T: Pepstatin A attenuates the inhibitory effect of $\mathrm{N}$-acetyl-Lcysteine on proliferation of hepatic myofibroblasts (stellate cells). Eur J Pharmacol 2002, 451:265-270

40. Okuyama H, Shimahara Y, Kawada N, Seki S, Kristensen DB, Yoshizato K, Uyama N, Yamaoka Y: Regulation of cell growth by redox-mediated extracellular proteolysis of platelet-derived growth factor receptor $\beta$. J Biol Chem 2001, 276:28274-28280

41. Osawa $Y$, Seki E, Adachi M, Suetsugu A, Ito H, Moriwaki H, Seishima M, Nagaki M: Role of acid sphingomyelinase of Kupffer cells in cholestatic liver injury in mice. Hepatology 2010, 51:237-845

42. Langmann T, Buechler C, Ries S, Schaeffler A, Aslanidis C, Schuierer M, Weiler M, Sandhoff K, de Jong PJ, Schmitz G: Transcription factors Sp1 and AP-2 mediate induction of acid sphingomyelinase during monocytic differentiation. J Lipid Res 1999, 40:870-880

43. Murate T, Suzuki M, Hattori M, Takagi A, Kojima T, Tanizawa T, Asano H, Hotta T, Saito H, Yoshida S, Tamiya-Koizumi K: Up-regulation of acid sphingomyelinase during retinoic acid-induced myeloid differentiation of NB4, a human acute promyelocytic leukemia cell line. J Biol Chem 2002, 277:9936-9943

44. Santana $P$, Peña LA, Haimovitz-Friedman A, Martin S, Green D, McLoughlin M, Cordon-Cardo C, Schuchman EH, Fuks Z, Kolesnick $R$ : Acid sphingomyelinase-deficient human lymphoblasts and mice are defective in radiation-induced apoptosis. Cell 1996, 86:189-199

45. Lang PA, Schenck M, Nicolay JP, Becker JU, Kempe DS, Lupescu A, Koka S, Eisele K, Klarl BA, Rübben H, Schmid KW, Mann K, Hildenbrand S, Hefter H, Huber SM, Wieder T, Erhardt A, Häussinger D, Gulbins E, Lang F: Liver cell death and anemia in Wilson disease involve acid sphingomyelinase and ceramide. Nat Med 2007, 13:164-170

46. Teichgräber V, Ulrich $\mathrm{M}$, Endlich $\mathrm{N}$, Riethmüller J, Wilker B, De Oliveira-Munding CC, van Heeckeren AM, Barr ML, von Kürthy G, Schmid KW, Weller M, Tümmler B, Lang F, Grassme H, Döring G, Gulbins E: Ceramide accumulation mediates inflammation, cell death and infection susceptibility in cystic fibrosis. Nat Med 2008, 14:382-391

47. Petrache I, Natarajan V, Zhen L, Medler TR, Richter AT, Cho C, Hubbard WC, Berdyshev EV, Tuder RM: Ceramide upregulation causes pulmonary cell apoptosis and emphysema-like disease in mice. Nat Med 2005, 11:491-498

48. Sommerfeld A, Reinehr R, Haussinger D: Bile acid-induced EGFR activation in quiescent rat hepatic stellate cells can trigger both, proliferation and apoptosis. J Biol Chem 2009, 284:22173-22183

49. Schuchman EH: The pathogenesis and treatment of acid sphingomyelinase-deficient Niemann-Pick disease. J Inherit Metab Dis 2007, 30:654-663

50. Marathe S, Miranda SR, Devlin C, Johns A, Kuriakose G, Williams KJ, Schuchman EH, Tabas I: Creation of a mouse model for non-neurological (type B) Niemann-Pick disease by stable, low level expression of lysosomal sphingomyelinase in the absence of secretory sphingomyelinase: relationship between brain intra-lysosomal enzyme activity and central nervous system function. Hum Mol Genet 2000, 9:1967-1976

51. Gupta S, Natarajan R, Payne SG, Studer EJ, Spiegel S, Dent P, Hylemon PB: Deoxycholic acid activates the c-Jun N-terminal kinase pathway via FAS receptor activation in primary hepatocytes. Role of acidic sphingomyelinase-mediated ceramide generation in FAS receptor activation. J Biol Chem 2004, 279:5821-5828

52. Canbay A, Guicciardi ME, Higuchi H, Feldstein A, Bronk SF, Rydzewski R, Taniai M, Gores GJ: Cathepsin B inactivation attenuates hepatic injury and fibrosis during cholestasis. J Clin Invest 2003, 112:152-159 